\title{
Overcommunication Strategies of Violating Grice's Cooperative Principle in Ground Service
}

\author{
Liu Xiaoqin ${ }^{1}$ \\ ${ }^{1}$ School of English for International Business, Guangdong University of Foreign Studies, Guangzhou, China \\ Correspondence: Liu Xiaoqin, Room 2101, Building A2, Huajingli, Huajingxincheng, Tianhe District, \\ Guangzhou 510630, Guangdong province, China. Tel: 18925150380. E-mail: 15552016@qq.com
}

Received: September 2, 2017

Accepted: October 15, 2017 Online Published: October 18, 2017

doi: 10.5539/elt.v10n11p162

URL: http://doi.org/10.5539/elt.v10n11p162

\begin{abstract}
Based on four maxims of Grice's cooperative principle framework, a small scale study is conducted to examine the communication strategies employed by experienced ground service staff. Data have been collected from questionnaires and in -depth interviews with Chinese domestic airlines' ground staff. This study identifies that the communicative challenges usually happen in service failure and service recovery. And it finds out violation of four maxims of Grice's cooperative principle is taken as sub-strategies of overinformativeness, telling a white lie, irrelevance, and ambiguity or prolixity. These strategies lead to overcommunication which could be routinely employed for the specific professional purposes of saving the passenger's face, gaining the passenger's understanding, reducing conflicts, avoiding complaints, or even establishing a harmonious relationship with passengers. This study moreover exploits that in the ground service communication context, two salient reasons stimulate the overcommunication strategies. Firstly it is to improve the service quality and secondly to enhance the passenger's satisfaction which are the determining factors to the sustainable development of the airlines. This study is ambitious to seek a new means of understanding and investigating the ground service communication from the perspective of pragmatics. By integrating business communication in ESP context to the classical theory of pragmatics, this study attempts to offer practical suggestions to the frontline communicators.
\end{abstract}

Keywords: overcommunication, Grice's cooperative principle, conversational implicature, service quality, passenger's satisfaction, ground service communication

\section{Introduction}

China has been the second largest aviation market in the world in terms of the volumes of passengers and air cargo moved in its domestic market since 2007 (Jiang \& Zhang, 2016). With the development of Chinese Belt and Road Initiative, the airlines have recently been playing a crucial role in transporting people and cargoes all over the world. Airline companies, however, face stiffening competition and are beset with problems arising from economic fluctuations and world political instability (Low \& Lee, 2014). Despite such problems, they try to retain a pool of satisfied and loyal passengers through both effective ground and in-flight service delivery and complaint-handling processes. It is not surprising that service quality and service recovery efforts contribute to customers' satisfaction and loyalty in the service industries (Whiting et al., 2011), and so do the airlines industry (Chen \& Chang, 2005; Hvass \& Torfadottir, 2014 ).

Front-line service delivery systems of air transportation may be generally divided into airport (ground) service and in-flight service. Ground staff members are expected to welcome passengers, deal with reservations, ticket purchases and check-in, carry out transactions associated with boarding and disembarkation procedures, respond to passenger requests or problems, and provide post-flight services etc. Therefore, ground staff members of airline companies are quite considered to be front-line employees and play a salient role in service delivery and complaint-handling processes (Yang \& Chang, 2012). Although passengers coming from all over the world may be native or non-native speakers of English, there is no doubt that English as a lingua franca is commonly used at the airports. Ground staff deal with routine work and variety of unexpected emergencies daily through face to face communication with passengers, which requires that ground staff must be good at communicating in English, in order to serve passengers well.

The study finds out many ground staff in the Chinese domestic airlines have good English learning background. In other words, their language competence is qualified enough to communicate with the passengers in English. 
However, there are still many complaints about the communication or service in ground service which damage the passenger's good impression on the airlines and may lead to the loss of the passengers in the long run. By the questionnaire survey, this study attempts to address this problem by identifying when the communication challenges often occur and what is accordingly communication strategies which help communicate effectively with designated professional purposes. Besides, in-depth interviews are next conducted to underpin what are the implied salient reasons for the employment of strategies which intentionally flout Gricean four maxims.

\section{The Related Studies}

\subsection{Grice's Cooperative Principle and Violation of Four Maxims}

Grice $(1975,1989)$ assumes that humans tend to cooperate with one another when communicating (Cooperative Principle) and they do so by conforming to a number of conversational maxims. According to Grice (1975:45) cooperative principle which consists of four maxims (maxim of quantity, quality, relation and manner) are the suggested principle for the speaker and the hearer to show their cooperation by giving appropriate contributions in their conversation. Table 1 illustrates these maxims and their sub-taxonomies that participants in the conversation should and normally conform to in order to cooperate with each other effectively.

Table 1. Grice's categories of cooperative principle and relevant maxims (Grice, 1975: 45-46).

\begin{tabular}{ll}
\hline Category & Maxims \\
\hline Quantity & 1. Make your contribution as informative as is required. \\
& 2. Do not make your contribution more informative than required. \\
Quality & Try to make your contribution one that is true: \\
& 1. Do not say what you believe to be false. \\
& 2. Do not say that for which you lack adequate evidence. \\
& Be relevant. \\
Relation & Be perspicuous: \\
Manner & 1. Avoid obscurity of expression. \\
& 2. Avoid ambiguity. \\
& 3. Be brief. \\
& 4. Be orderly \\
\hline
\end{tabular}

According to Grice (1975), the purpose of cooperative principle is to get effective communication as informative as clearly. In a conversation a speaker and a hearer are supposed to respond to each other in their turn with the needed information that benefits both of them. By giving the required information, they can understand each other's utterances. By conforming to cooperative principle and its maxims, the speaker allows the hearer to draw assumptions about the speaker's intentions. Thereafter, cooperative principle is widely applied to exploiting both written and spoken texts. Nevertheless, people sometimes may not fulfill these maxims and seem to disobey them in a certain context. Grice (cited in Cutting, 2002, p. 40) says that when the speaker does not fulfill the maxims, the speaker is said to "violate" them.

Violation is a condition where the speaker does not purposefully fulfill certain maxims for some other purposes. Grice notices that violation of his maxims takes place when the speaker intentionally refrains from applying maxims in their conversation. Scholars have fully discussed diverse reasons of violation of maxims. Grice (1975: 49) underlines that when the speaker refrains from applying his maxims, the speaker is "liable to mislead" their counterparts in conversation. Goffman (2008: 17) says that the speaker does not abide by Gricean maxims in order to save face. Chirstoffersen (2005) also argues that in real life situation, people violate the maxims for different reasons. Khosarvizadeh and Sadehvandi (2011: 122-123) say that the speaker violates Grice's maxims in order to cause misunderstandings on their participants' part to achieve some other purposes, for example to please counterpart, evade discussion, avoid unpleasant condition, and express feelings.

Until now, Grice's cooperative principle has been widely employed to do discourse analysis including movie dialogues, literature, legal documents, novel dialogues and business negotiation etc. The previous studies mainly focus on exploiting flouting of cooperative principle and maxims by examining transcription data and further 
exploiting the conversational implicature. This study however endeavors to discuss violation of maxims as communication strategies from the perspective of business communication in the field of English for specific purposes (ESP), which does not examine the conversation but does case studies. Grice (1989: 26) clearly states "Make your conversational contribution such as is required, at the stage at which it occurs, by the accepted purpose or direction of the talk exchange in which you are engaged". Besides this requirement, other parameters in the field of ESP such as communication context, disciplinary requirements, professional practice and institutional culture also become crucial. Therefore, this study, based on the Gricean maxims, simultaneously takes these factors into consideration. For instance, we originally tend or are expected to be truthful in our exchanges with others by following the maxim of quality (Grice, 1989: 27). However, if we do so, it will cause troubles in specific communication context. Hence there must be a convincingly context -based reason for flouting these maxims which gives rise to implied meanings or particular purposes fitting for the present communicative stage. With that, this study is ambitious to integrate Gricean cooperative principles to the communicative context of the ground service, which must be a new endeavor in the domain of cooperative principle study.

As mentioned above, if the speaker does not conform to the cooperative principle, some conversational implicature may produce. He (2003: 65) argues that the cooperative principle is followed reasonably, not compulsorily. The speaker may violate the cooperative principle deliberately but without making the hearer realize it. In this case, the speaker is most likely to mislead the hearer. For example, when someone is telling a lie, he violates the quality maxim by saying untrue things. But if the hearers does not realize this and assumes that the speaker follows the cooperative principle. He will be misled. However, in different social context, we are supposed to think over the real purpose of the lie and why the speaker intentionally wants to mislead the hearer. The speaker may face dilemma. On the one hand, he wants to hold the quality maxim the present stage requires. While on the other hand, there is a possibility that other maxims will be violated or the real communicative purposes will not be achieved if the quality maxim is held, so there is a clash here. At this moment, the speaker must think over the authentic communication purpose which may motivate the speaker to violate one maxim or conform to the others. In doing so, the implicature is generated in a conversation by overtly and deliberately violating some submaxims for communicative purposes (He, 2003: 73). They are inferences dependent on particular time, place and people. This study wants to reveal the true communicative reasons in the context of ESP.

\subsection{The Perspectives of Service Quality and Passenger's Satisfaction}

According to the official report of the Civil Aeronautics Administration (CAA) in China, there are three main dimensions that airlines use to plan for future development: safety, service, and satisfaction (the "3Ss"). The dimension of safety sounds no relevance with the present study. In reviewing the recently conducted research, it is commonplace to discover studies on another two topics: service (Chen \& Wu, 2009; Liou \& Tzeng, 2007; Lu \& Ling, 2008; Sim et al., 2006; Tiernan et al., 2008), and satisfaction (Gkritza et al., 2006; Lopez-Bonilla \& L opez-Bonilla, 2008; Lu \& Ling, 2008).

Service quality refers to consumers' subjective impressions regarding the efficiency and effectiveness of the service delivery process provided by a service provider (Chen \& Chang, 2005; Park et al., 2004). While service quality has been studied widely in the literature, its attributes are still open for further discussion and typically depend on the context targeted by the researcher (Liou \& Tzeng, 2007). Therefore, finding ways to properly measure service quality has been a difficult issue for both researchers and industrial practitioners, including the airline industry (Gursoy et al., 2005; Park et al., 2004). Empirical studies claim that service quality is generally the key to improving operational performance and competitive advantage as well as to generating profits and market share (Caruana, 2002; Cronin \& Taylor, 1992; McDougall and Levesque, 2000; Parasuraman et al., 1994; Teas, 1994; Wilkins et al., 2007). In terms of the airline industry, related studies argue that providing outstanding service may lead to airlines' long-term development (Morash \& Ozment, 1994; Zeithaml et al., 1996), and sustain competitive advantage (Chen, 2008), and even survive (Park et al., 2006). Airline service quality may be viewed as a driver of passenger satisfaction, loyalty, and airline selection (Park et al., 2006). Mustafa et al. (2005) indicate that one of the most crucial factors in maintaining an airline's operations is the improvement of service quality for its passengers. In light of the above, the delivery of outstanding service becomes a critical marketing requirement for most, if not all, airline companies, as competitive pressures in the airline industry continue to increase (Andotra \& Gupta, 2008; Ostrowski et al., 1993). Although there are quite a lot of studies on service quality from different perspectives, this study mainly holds that the employment of communicative strategies may result in the better service quality at the airports.

Because the attributes of service quality are still open for discussion in the literature and vary depending on the 
studied context (Liou \& Tzeng, 2007), there is currently no specific method for measuring service quality (Chen \& Chen, 2010a, b; Stanley \& Wisner, 2002). Specifically, Park et al. (2004) find that many airlines have difficulty in applying a suitable instrument and/or approach to service quality and thereby adequately appraising and improving service effectiveness. Chinese domestic airlines may have the same embarrassment and some airlines are trying to evaluate the service quality by means of the rate of passengers' complaints. In order to reduce the complaints as much as possible and improve the service quality, there are many measures taken by domestic airlines. For example, China Southern Airlines trains the ground staff regularly and has drafted a test system of communicative competence for ground staff, which ambitiously assesses ground staff's communicative competence in English. Besides these efforts, this study attempts to examine the service quality from a new perspective of Grice's cooperative principle which underpins the interaction and communication itself and adapts to the specific discipline. Moreover, overcommunication is firstly tentatively put forward as a measurable assessment for the ground staff's service quality.

\section{Methods}

\subsection{Research Questions}

The present study attempts to identify communication strategies and the real reasons for the employment of these communication strategies, which is ambitious to contribute to professional communication in the field of ESP. With the general research goal, three research questions will be specifically addressed:

When do communication difficulties often occur, during the normal routine service, service failure, or service recovery?

What commumication strategies of violation of Gricean Maxims are employed by ground service staff to improve communication with the passengers?

Why do they employ these communication strategies in the context of ground staff service?

\subsection{Data Collection}

This research is conducted in two stages including the questionnaire survey and in-depth interviews. Questionnaires are a useful method for soliciting individual perception and interpretation of daily communication with passengers. The first stage involves the distribution of highly structured and closed questionnaires, an efficient means of identifying when ground staff face the challenges, how they violate or observe the maxims of cooperative principle to overcome the challenges, and why they violate or observe these maxims while communicating with passengers. The second stage is semi-structured in-depth interviews seeking more "thick" and detailed data, as Punch (2009) argues that the interviews are seen as a powerful way of gaining understanding of others and accessing their perceptions and constructions of reality. In particular, the in-depth interviews help find more field cases from the front-line workplace.

The questionnaire is composed of three sections, which seeks information about the English competence of the surveyed staff and their communication experiences in order to develop a body of data that could contribute to finding out the situations of communication challenges and defining the communication strategies employed by ground staff. Tightly following the structure of a survey conducted by Harsch (2012), the first section focuses on demographic information. The second and third sections require participants to rate the frequency of occurrence of communication challenges and the strategies employed by them with using a Likert scale from 1 to 5 ( 1 as "never occurs" and 5 being "occurs very often"). Moreover, the third section includes statements of the strategies which may be used by experienced ground staff. These strategies listed in the questionnaire are carefully pre-selected items drawn from the previous literature (Hansson, 2015), and adapted from some pragmatic strategies violating Gricean maxims. In addition, respondents are given the opportunity to note that some communication strategies that they used but are not included in the questionnaire.

\section{Results and Discussion}

Aiming to obtain rich and detailed data that may lead to a greater level of understanding of the pragmatic interaction between ground staff and passengers, and to generate insights into the conversational implicature or purposes of their communication, this study distributes 200 questionnaires through e-mail, we-chat, or QQ into ground staff in several Chinese domestic airlines. And eventually 121 completed questionnaires have been received and then analyzed. The respondents of the survey are experienced ground staff of Chinese domestic airlines. As required by these respondents, their names and airlines' names are not allowed to disclose. Among 121 questionnaire participants, 15 participants are randomly selected to take part in the interviews. Due to the objective reasons of distance and time, some interviews take place face or face, while some have been done through we-chat. 
The demographic information (Table 2) obtained from the first part of questionnaires is intended to identify the education background, English proficiency, the years of working, and the frequency of speaking English as a lingua franca at workplace, so as to get a greater understanding of the respondents' language competence. The collected data indicate that most of ground staff have good education background, with 75 staff out of 121 respondents holding the bachelor degree or above. And their English competence of surveyed staff sounds to be also much qualified, because all of these respondents have passed CET4. A majority of staff have a certificate of CET6 which means their English ability should be intermediate. It is noticeable that there are 33 staff whose English is very excellent with certificates of TEM4 or TEM8. Data also show that all the staff have been working for less than 5 years but most of them work for more than 3 years Furthermore, they communicate with foreign passengers in English as lingua franca more than 3 days a week. In conclusion, demographic information demonstrates that these staff are not newcomers but more or less experienced in communicating with foreign passengers and their English competence theoretically sounds to fit for their duties. In other words, communication challenges may not arise due to their poor English proficiency.

Table 2. Demographic information

\begin{tabular}{|c|c|c|c|c|}
\hline Highest level of education attainment & $\begin{array}{l}\text { College } \\
\text { degree }\end{array}$ & bachelor & postgraduate & $\begin{array}{l}\text { Master level and } \\
\text { above }\end{array}$ \\
\hline Respondents & 46 & 73 & 2 & 0 \\
\hline English certificate & CET4 & CET6 & TEM4 & TEM 8 \\
\hline Respondents & 121 & 75 & 23 & 10 \\
\hline Working years & $\begin{array}{l}\text { Less than one } \\
\text { year }\end{array}$ & $1-3$ years & 4-5years & $\begin{array}{l}\text { More than } \\
\text { years }\end{array}$ \\
\hline Respondents & 23 & 20 & 78 & 0 \\
\hline $\begin{array}{l}\text { Frequency of communicating with } \\
\text { passengers in English }\end{array}$ & Daily & $\begin{array}{l}4-6 \text { days a } \\
\text { week }\end{array}$ & $\begin{array}{l}1-3 \text { days a } \\
\text { week }\end{array}$ & Hardly \\
\hline Respondents & 0 & 115 & 8 & 0 \\
\hline
\end{tabular}

Note: CET4, CET 6, TEM 4, and TEM 8 are the English proficiency test for Chinese college students. Among them, CET 4 and CET 6 are designed for non-English majored students. And TEM 4 and TEM 8 are for English majored students.

\subsection{Situations of the Occurrence of Communication Challenges}

The results from the second section of the questionnaire address the first research question. It is found that challenges rarely occur in the normal routine service but often happen in the process of service failure and service recovery.

Table 3. Situations of occurrence of challenges from very often (5) to never (1)

\begin{tabular}{ll}
\hline The specific situations when challenges happen & Mean frequency \\
\hline $\begin{array}{l}\text { Challenges arise when the ground service goes smooth. } \\
\text { Challenges arise when the passenger makes an enquiry with you }\end{array}$ & 2 \\
$\begin{array}{l}\text { Challenges arise when you fail to serve the passenger due to the airlines' subjective } \\
\text { faults such as overbooking, luggage damage or luggage loss etc. }\end{array}$ & 4 \\
$\begin{array}{l}\text { Challenges arise when you fail to serve the passenger due to force majeure, such as } \\
\text { bad weather, engine breakdown, or air control etc. }\end{array}$ & 4 \\
$\begin{array}{l}\text { Challenges arise when you refuse the passenger due to the passenger's unreasonable } \\
\text { requirements, such as oversized luggage, free upgrade, or jumping the queue etc. }\end{array}$ & 3 \\
\begin{tabular}{l} 
Challenges arise after service failure, such as flight delay, or flight cancellation etc. \\
\hline
\end{tabular} & 5 \\
\hline
\end{tabular}


On one hand, when the routine service goes smooth, there are few communication challenges. On the other hand, when the ground staff fail to serve the passengers because of variety of reasons such as airlines' subjective mistakes of overbooking, luggage damage or luggage loss etc. or force majeure of bad weather, engine breakdown, or air control etc., it is much easier to cause communication challenges. It is noticeable that when passengers put forward the unreasonable requirements, the rate of communication challenges is little lower than another situations of service failure. Service recovery after the service failure sounds to be thorny, as the data show that challenges very often arise when there is a flight delay or flight cancellation.

\subsection{Communication Strategies of Violating Gricean Maxims}

With these challenge situations, it is reasonable to make a doubt what are the communication strategies ground staff employ to handle them. This study addresses it from the perspective of Gricean cooperative principle and its maxims. In terms of four maxims, four macro-strategies are accordingly pre-devised by fitting in the context of ground service in the questionnaire. Data show that all the strategies mentioned in the questionnaire have been more or less used by the ground staff, even if the frequency of employment varies.

\subsubsection{Overinformativeness: Violation of the Maxim of Quantity}

Table 4. Sub-strategies of overinformativeness from very often (5) to never (1)

\begin{tabular}{ll}
\hline Sub-Strategies & Mean frequency \\
\hline Offer more information than the passenger wants & 5 \\
Offer less information than the passenger wants & 2 \\
Offer help more than what your duty requires & 4 \\
$\begin{array}{l}\text { Explain to the passenger more patiently or carefully than the duty requirements } \\
\text { until the trouble is to be solved }\end{array}$ & 5 \\
\hline
\end{tabular}

The questionnaire data demonstrate that the ground staff always intentionally or unintentionally take the strategy of overinformativeness through diversity of forms. It sounds that they get used to offering more information than the passenger wants rather than less information. And they often provide help which may go beyond their duty requirements, until the passenger's trouble is solved. These communication means definitely flout the quantity maxim.

\subsubsection{Telling a White Lie: Violation of the Maxim of Quality}

Table 5. Sub-strategies of telling a white lie from very often (5) to never (1)

\begin{tabular}{ll}
\hline Sub-strategies & Mean frequency \\
\hline $\begin{array}{l}\text { Hold some true information back when you know the information will make the } \\
\text { passenger worried or irritated }\end{array}$ \\
$\begin{array}{l}\text { Say something which you lack adequate evidence in order to comfort the } 4 \\
\text { passenger }\end{array}$
\end{tabular}

The data against the principle of being honest obviously violate the quality maxim. In general, the airlines are supposed to disclose any information to the passengers, no matter how good or bad the information is. From these respondents, they often choose to hold some true information back when they know the information will make the passenger worried or irritated. Or they also say something which they lack adequate evidence in order to comfort the passenger. Although these communication seriously flout the quality maxim, they sound to be reasonable at the present stage of ground service if the passenger can feel happy or relaxed. In fact, these communication may please the passenger and avoid conflicts so as to be viewed as an effective communication.

\subsubsection{Irrelevance: Violation of the Maxim of Relation}


Table 6. Sub-strategies of irrelevance from very often (5) to never (1)

\begin{tabular}{ll}
\hline Sub-strategies & Mean frequency \\
\hline Indirectly refuse the passenger's unreasonable request & 5 \\
In order to avoid conflicts or hide some unhappy information, communicate some & 3.7 \\
information irrelevant, for example a small talk, a joke, or an irrelevant chat etc. & \\
\hline
\end{tabular}

These two sub-strategies in Table 6 are employed by the respondents to refuse the passenger's unreasonable request, hide some unhappy information or avoid conflicts. It seems that direct refusal of the passenger's request, even unreasonable, is not the professional practice in service industry, as it may lead to unhappiness or misunderstanding of the passenger so as to damage the relationship. The survey shows that experienced staff dare violate the relation maxim and make their refusal more indirect. In doing so, they lessen damage to the passenger and save the passenger's face.

\subsubsection{Ambiguity or Prolixity: Violation of the Maxim of Manner}

Table 7. Sub-strategies of ambiguity or prolixity from very often (5) to never (1)

\begin{tabular}{ll}
\hline Sub-strategies & Mean frequency \\
\hline Offer an ambiguous respond to the passenger & 3.6 \\
Use some ambiguous terms, such as about, maybe, or approximate etc. & 5 \\
$\begin{array}{l}\text { Explain the unfavorable information as much as possible in order to gain the } \\
\text { understanding of the passenger }\end{array}$ & 5 \\
Repeat something until the passenger understands you & 5 \\
\hline
\end{tabular}

From the data in Table 7, it is found that most ground staff may offer an ambiguous response to the passenger. Moreover $100 \%$ ground staff use some ambiguous terms such as about, maybe, or approximate to make their information less accurate, which obviously violates the maxim of manner. And the ground staff explain the unfavorable information as much as possible and repeat information until the passenger understands, which also flouts the maxim of being brief. There must be some implied reasons for these professional practices.

\subsection{Reasons for Overcommunication Strategies of Flouting Gricean Maxims}

Questionnaire data obviously disclose that the experienced ground staff take some strategies to deal with the communication challenges occurring in the service failure and service recovery. These strategies are identified to clearly flout Gricean maxims. It sounds controversial to the cooperative principle which is proposed by Grice to make an effective communication between the participants. However by taking the specific communicative purposes in the context of ESP into consideration, this study manages to find out the real reasons of flouting these maxims. The in-depth interviews with 15 interviewees provide some detailed front line cases which help underpin the exact reasons for overcommunicaition in the ground service. In order to fully illustrate the specific reasons, some typical cases will be discussed.

\subsubsection{Ovecommunication for Improving Service Quality}

The maxim of quantity has two sub-maxims: (a) make your contribution as informative as is required for the current purposes of the exchange; (b) do not make your contribution more informative than is required (Grice, 1989: 26).

Case one: When a passenger asked for the direction of boarding gate 211, I firstly directly showed the way to the passenger and I usually asked more about his flight information for confirmation. (Interviewee 1)

In the case situation, the passenger is to find out the boarding gate 211 , and the ground staff shows him the way. Until then, the conversation is supposed to be end because the passenger achieves his communicative purpose of finding the way to the boarding gate. However, the ground staff asks for more flight information to confirm whether the boarding gate is right, which makes his communication more informative than is required. From the passenger's view, he must be very happy with the oversupplied service which makes him feel confirmed with his flight and boarding gate. In general, the overinformativeness is usually appreciated by a passenger, which makes 
a good impression on good service quality.

There are two sub-maxims in the quality: (a) Do not say what you believe to be false; (b) Do not say that for which you lack adequate evidence (Grice, 1989: 26). Some interviewees confess that they sometimes tell a white lie with the purpose of comforting the passengers. One specific example is cited by an interviewee.

Case two: An elderly passenger was waiting for her flight and looked very nervous. I went over to her and planned to offer help if needed. In order to make the elderly passenger ease, I said: "do not worry about the flight, it must be very comfortable and smooth". In fact, I could not assure what I said to her. (Interviewee 2)

In the case, the interviewee comforts the elderly passenger without any proof, because the interviewee cannot judge the situation of the passenger's flight due to many unexpected reasons such as turbulence. Therefore, he intentionally tells a lie. However, his lie in the above situation shows his care to the elderly passenger and may make her less afraid of the flight and feel better. In doing so, he establishes the harmonious relationship with the passenger which can also be regarded as an indicator of good service quality.

\subsubsection{Ovecommunication for Enhancing the Passenger's Satisfaction}

Grice (1989: 27) argues that cooperative behavior involves following the maxim of relation ("Be relevant"), but admits that identifying the (changing) meanings of "relevance" in the course of particular transactions in various contexts can be "exceedingly difficult". There is one more case which can be used to illustrate the violation of relation.

Case three: One economic class passenger insisted on checking in at the VIP counter. When he was refused, he asked, "why cannot I check in here"? I answered, "Dear sir, your check-in counter was L12. If you could not find out, I am glad to guide you there. Thanks". (Interviewee 3)

Goffman, $(1955,1967)$ states that people sometimes depart from the Gricean Maxims because of observing the listener's face. In this case, if interviewee 3 directly answers the passenger's question and says "Sir, this is VIP check-in counter. You only buy an economic class ticket, so you have no priority to enjoy VIP check-in service". The passenger's face may be damaged and thus it may cause dissatisfaction to the service. However in the case, the interviewee says nothing relevant about the refusal reason, but solves the problem tactically. In doing so, the response of the interviewee obviously violates the maxim of being relevant. However, in the practical ground service, the ground staff respects the passenger's face and avoids making the passenger embarrassed so as to make dissatisfaction, which helps solve the problem harmoniously.

The maxim of manner - a maxim concerning the "how" of interaction - is formulated simply as: be perspicuous. It has four sub-maxims: (1) avoid obscurity of expression; (2) avoid ambiguity; (3) be brief (avoid unnecessary prolixity); (4) be orderly (Grice, 1989: 27).

The interview data clearly identify the ambiguity of the communication between the ground staff and the passenger. It is worth noting that, at least in certain cultures, ambiguity tends to be regarded as a strictly negative feature of text and talk, often linked to an assumption that people can conceal a fact or a purpose by obscuring their meaning with verbiage. The talks discover ground staff usually conceal some accurate information with a certain purpose. One case is stated as follows:

Case four: The flight was announced to be delayed. The passengers waited for new boarding information. Some passengers felt worried or anxious and kept on asking when they could board. I said with big a smile, "should be very soon, please wait for a moment. I am very sorry and thank you for your patience". (Interviewee 4)

In the handling of the communication challenge, this ground staff with certain purposes answers the question ambiguously and unbriefly, which apparently fails to observe the maxim of manner. The interviewee explains that although the answer of "should be very soon" is unclear, it may help reduce the passenger's chaos or blames at the present communicative stage which may function in lessening the passenger's blames and dissatisfaction at this moment.

It is well-known that the nature of good ground service is passenger centered. In order to improve the passenger's satisfaction, it is very crucial to make the passenger feel safe and happy with flying with a certain airline company. These cases illustrated above all violate one or more maxims of $\mathrm{CP}$, but they sound to be effective communication which shows sincere care to the passengers, pleases the passengers, saves the passengers' face, reduces their blames, and so establishes a harmonious relationship with the passengers in the context of ground service. Therefore in fact, it suggests that overcommunication of violation of maxims may help improve the service quality and enhance the passengers' satisfaction which are two crucial factors for the development of the airlines. 


\section{Conclusion}

Based on the Gricean maxims, the present study takes ground staff as the surveyed group and is ambitious to shed lights on the communicative strategies in the context of ground service. This study has the following findings: 1) When the routine service goes smooth, the communication challenges hardly occur. However, to be noticeable, the challenges often occur in the service failure or service recovery. 2) While facing these communication problems, the ground staff usually take overcommunication strategy to handle them. Specifically Overinformativeness, telling a white lie, irrevelance, and ambiguity and prolixity are widely employed by ground staff in the ground service communication context. 3) Violation of Gricean maxims must produce some conversational implicature. In the present study, two general reasons have been identified are to improve service quality and enhance the passenger's satisfaction which fit for the development of the airlines.

This study is a new endeavor to discuss the important theory of pragmatics from the perspective of ESP and integrate linguistics theory to the business communication in a professional context. These findings may add more pragmatic implicature to the current communicative competence for ground staff. In particular, overcommunication can be a new concept for the business service industry practitioners to improve their communication. And four sub-strategies identified in the present study are suggested to be widely applied in effective communication in front line workplace.

From a pedagogical perspective, it would seem appropriate for trainers to equip ground staff with a greater understanding of ESP contexts. The findings show that besides the language proficiency, the pragmatic strategies in communication are even more important to facilitate effective communication in the ESP context. As Kubota's (2013) argument that teachers need to focus on helping language learners communicate more effectively in English with interlocutors from other countries, the trainers of ground staff are suggested to train ground staff both linguistic and pragmatic strategies in order to conform to the professional practice.

\section{Acknowledgments}

This paper is supported by the postgraduate innovative project of Guangdong University of Foreign Studies (16GWCXXM-30).

\section{References}

Andotra, N., \& Gupta, S. (2008). Airline service effectiveness: an analysis of value addition, quality and risk perception. Abhigyan, 26, 10 -19.

Caruana, A. (2002). Service loyalty: the effects of service quality and the mediating role of customer satisfaction. Eur. J. Mark, 36, 811-830. https://doi.org/10.1108/03090560210430818

Chen, C. (2008). Investigating structural relationships between service quality, perceived value, satisfaction, and behavioral intentions for air passengers: evidence from Taiwan. Transp. Res. A Policy Pract, 42, 709-717. https://doi.org/10.1016/j.tra.2008.01.007

Chen, C., \& Wu, T. (2009). Exploring passenger preferences in airline service attributes: a note. J. Air Transp. Manag, 15, 52-53. https://doi.org/10.1016/j.jairtraman.2008.07.005

Chen, F. Y., \& Chang, Y. H. (2005). Examining airline service quality from a process perspective. J. Air Transp. Manag, 11(2), 79-87. https://doi.org/10.1016/j.jairtraman.2004.09.002

Chen, J. K., \& Chen, I. S. (2010a). Aviation innovation system construction using a hybrid fuzzy MCDM model. Expert Syst Appl, 37, 8387 -8394. https://doi.org/10.1016/j.eswa.2010.05.043

Chen, J. K., \& Chen, I. S. (2010b). Disparities between services demanded and services received in Taiwanese restaurants. Glob J. Bus Res, 4, 59-69.

Chirstoffersen. (2005). White lies. Retrieved June 2nd 2016, from http://www.petra.ac.id/ puslit/journals/dir.php?DepartmentID=ING

Cronin, J. J., \& Taylor, S. A. (1992). Measuring service quality: a reexamination and extension. J. Mark, 56, 55-68. https://doi.org/10.2307/1252296

Cutting, J. (2002). Pragmatics and Discourse. A Resource Book for Students. London: Routledge.

Goffman, E. (1955). On face-work: an analysis of ritual elements in social interaction. Psychiatry, 18(3). 213-231. https://doi.org/10.1080/00332747.1955.11023008

Goffman, E. (1967). Interaction Ritual: Essays on Face-to-Face Behavior. New York: Doubleday.

Goffman, E. (1974). Frame Analysis: An Essay on the Organization of Experience. Cambridge, MA: Harvard 
University Press.

Goffman, E. (2008). Interaction Ritual: Essays on Face-to-Face Behavior. Far Hill: Pantheon Books.

Grice, H.P. (1969). Utterer's meaning and intentions. Philos. Re, 78, 147-177. https://doi.org/10.2307/2184179

Grice, H. P. (1975). Logic and conversation. In P. Cole, \& J. L. Morgan (Eds.), Syntax and Semantics, 3, New York: Academic Press. pp. 41-58.

Grice, H. P. (1989). Studies in the Way of Words. Cambridge, MA: Harvard University Press.

Gursoy, D., Chen, M., \& Kim, H. J. (2005). The US airlines relative positioning based on attributes of service quality. Tour. Manag, 26, 57-67. https://doi.org/10.1016/j.tourman.2003.08.019

Harsch, C. (2012). Intercultural competencies for the global workplace (Online). Coventry: University of Warwick.

Hasson, S. (2015) Calculated overcommunication: strategic uses of prolixity, irrelevance, and repetition in administrative language. The Journal of Pragmatics.

He, Z. R. (2003). Notes on Pragmatics. Najing Normal University Publishing House.

Hvass, K. A., \& Torfadottir, E. (2014). Spatially dispersed employee recovery: an airline case study. J. Air Transp. Manag, 34, 65-69. https://doi.org/10.1016/j.jairtraman.2013.08.003

Jiang, H. W., \& Zhang, Y. H. (2016). An investigation of service quality, customer satisfaction and loyalty in China's airline market. Journal of Air Transport Management, 80-88. https://doi.org/10.1016/j.jairtraman.2016.07.008

Khosravizadeh, P., \& Sadehvandi, N. (2011). Some instances of violations and flouting of the maxim of quantity by the main character (Barry and Tim) in Dinner for schmucks, IPEDR, 26, Singapore: IACSIT Press.

Kubota, R. (2013). 'Language is only a tool': Japanese expatriates working in China and implications for language teaching. Multilingual Education, 3, 1-20. https://doi.org/10.1186/2191-5059-3-4

Liou, J. J. H., \& Tzeng, G. (2007). A non-additive model for evaluating airline service quality. J. Air Transp. Manag, 13, 131-138. https://doi.org/10.1016/j.jairtraman.2006.12.002

Low, J. M. W., \& Lee, B. K. (2014). Effects of internal resources on airline competitiveness. J. Air Transp. Manag, 36, 23-32. https://doi.org/10.1016/j.jairtraman.2013.12.001

Lu, J., \& Ling, F. (2008). Cross-cultural perspectives regarding service quality and satisfaction in Chinese cross-strait airlines. J. Air Transp. Manag, 14, 16-19. https://doi.org/10.1016/j.jairtraman.2007.08.002

McDougall, G. H. G., \& Levesque, T. (2000). Customer satisfaction with services: putting perceived value into the equation. J. Serv. Mark, 14, 392 -410. https://doi.org/10.1108/08876040010340937

Morash, E. A., \& Ozment, J. (1994). Toward management of transportation service quality. Logist Transp Rev, 30, 115-140.

Mustafa, A., Fong, J. P., Lim, S. P., \& Hamid, H. A. (2005). The evaluation of airline service quality using the analytic hierarchy process (AHP). Paper Presented to the International Conference on Tourism Development. Malaysia, Penang.

Ostrowski, P. L., O'Brien, T. V., \& Gordon, G. L. (1993). Service quality and customer loyalty in the commercial airline industry. J. Travel Res, 32, 16 -24. https://doi.org/10.1177/004728759303200203

Parasuraman, A., Zeithaml, V. A., \& Berry, L. L. (1994). Reassessment of expectations as a comparison standard in measuring service quality: implications for further research. $J$. Mark, 58, 111-125. https://doi.org/10.2307/1252255

Park, J., Robertson, R., \& Wu, C. (2004). The effect of airline service quality on passengers' behavioural intentions: a Korean case study. J. Air Transp. Manag. 10, 435-439. https://doi.org/10.1016/j.jairtraman.2004.06.001

Park, J., Robertson, R., \& Wu, C. (2006). The effects of individual dimensions of airline service quality: findings from Australian domestic air passengers. J. Hosp. Tour. Manag, 13, 161-176. https://doi.org/10.1375/jhtm.13.2.161

Punch, K. F. (2009). Introduction to Research Methods in Education. London: Sage.

Stanley, L. L., \& Wisner, J. D. (2002). The determinants of service quality: issues for purchasing. Eur. J. Purch. 
Supply Manag, 8, 97-109. https://doi.org/10.1016/S0969-7012(01)00009-0

Teas, R. K. (1994). Expectations as a comparison standard in measuring service quality: an assessment of a reassessment. J. Mark, 58, 132-140. https://doi.org/10.2307/1252257

Whiting, A., Donthu, N., \& Baker, A. M. (2011). Investigating the immediate and longterm effects of job stressors on frontline service employees. Int. J. Res. Mar, 28(4), 319-331. https://doi.org/10.1016/j.ijresmar.2011.05.006

Wilkins, H., Merrilees, B., \& Herington, C. (2007). Towards an understanding of total service quality in hotels. Int. J. Hosp. Manag, 26, 840-853. https://doi.org/10.1016/j.ijhm.2006.07.006

Yang, C.-H., \& Chang, H.-L. (2012). Exploring the perceived competence of airport ground staff in dealing with unruly passenger behaviors. Tour. Manag, 33(3), 611-621. https://doi.org/10.1016/j.tourman.2011.07.001

Zeithaml, V.A., Berry, L.L., \& Parasuraman, A. (1996). The behavioral consequences of service quality. J. Mark, 60, 31-46. https://doi.org/10.2307/1251929

\section{Copyrights}

Copyright for this article is retained by the author(s), with first publication rights granted to the journal.

This is an open-access article distributed under the terms and conditions of the Creative Commons Attribution license (http://creativecommons.org/licenses/by/4.0/). 